\title{
Antipsychotic and benzodiazepine use and brain morphology in schizophrenia and affective psychoses - Systematic reviews and birth cohort study
}

\section{Huhtaniska, Sanna}

2018-11-30

Huhtaniska, S , Korkala , I, Heikka, T, Björnholm , L, Lehtiniemi , H, Hulkko , A P , Moilanen , J , Tohka , J Manjon , J , Coupe , P , Kiviniemi , V , Isohanni , M , Koponen , H , Murray , G K, Miettunen , J \& Jääskeläinen , E 2018 , ' Antipsychotic and benzodiazepine use and brain morphology in schizophrenia and affective psychoses - Systematic reviews and birth cohort study ' , Psychiatry Research. Neuroimaging , vol. 281 , pp. 43-52 . https://doi.org/10.1016/j.pscychr

http://hdl.handle.net/10138/306612

https://doi.org/10.1016/j.pscychresns.2018.08.015

publishedVersion

Downloaded from Helda, University of Helsinki institutional repository.

This is an electronic reprint of the original article.

This reprint may differ from the original in pagination and typographic detail.

Please cite the original version. 


\title{
Antipsychotic and benzodiazepine use and brain morphology in schizophrenia and affective psychoses - Systematic reviews and birth cohort study
}

\author{
Sanna Huhtaniska ${ }^{\mathrm{a}, \mathrm{b}, \mathrm{c}, *}$, Iikka Korkala ${ }^{\mathrm{a}, \mathrm{c}}$, Tuomas Heikka ${ }^{\mathrm{a}}$, Lassi Björnholm ${ }^{\mathrm{b}, \mathrm{c}}$, Heli Lehtiniemi ${ }^{\mathrm{a}}$, \\ Anja P. Hulkko ${ }^{\mathrm{a}, \mathrm{b}, \mathrm{c}}$, Jani Moilanen ${ }^{\mathrm{b}}$, Jussi Tohka ${ }^{\mathrm{d}}$, José Manjón ${ }^{\mathrm{e}}$, Pierrick Coupéf \\ Vesa Kiviniemi $^{\mathrm{g}}$, Matti Isohanni ${ }^{\mathrm{a}, \mathrm{c}, \mathrm{h}}$, Hannu Koponen ${ }^{\mathrm{i}}$, Graham K. Murray ${ }^{\mathrm{j}, \mathrm{k}}$, Jouko Miettunen ${ }^{\mathrm{a}, \mathrm{b}}$, \\ Erika Jääskeläinen ${ }^{\mathrm{a}, \mathrm{b}, \mathrm{h}}$
}

a Center for Life Course Health Research, University of Oulu, Finland

${ }^{\mathrm{b}}$ Medical Research Center Oulu, Oulu University Hospital and University of Oulu, Finland

${ }^{\mathrm{c}}$ Department of Psychiatry, Research Unit of Clinical Neuroscience, University of Oulu, Finland

d AI Virtanen Institute for Molecular Sciences, University of Eastern Finland, Finland

e Instituto de Aplicaciones de las Tecnologías de la Información y de las Comunicaciones Avanzadas (ITACA), Universitat Politècnica de València, Spain

${ }^{\mathrm{f}}$ Laboratoire Bordelais de Recherche en Informatique, Unité Mixte de Recherche CNRS (UMR 5800), PICTURA Research Group, France

${ }^{g}$ Department of Diagnostic Radiology, Oulu University Hospital, Finland

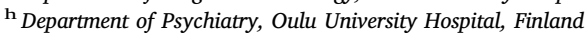

${ }^{\text {i } U n i v e r s i t y ~ o f ~ H e l s i n k i, ~ H e l s i n k i ~ U n i v e r s i t y ~ H o s p i t a l, ~ P s y c h i a t r y, ~ H e l s i n k i, ~ F i n l a n d ~}$

${ }^{\mathrm{j}}$ University of Cambridge, Department of Psychiatry, United Kingdom

${ }^{\mathbf{k}}$ University of Cambridge, Behavioural and Clinical Neuroscience Institute, United Kingdom

\section{A R T I C L E I N F O}

\section{Keywords:}

Schizophrenia

Affective psychoses

Brain

MRI

Psychopharmacology

\begin{abstract}
A B S T R A C T
The aim of this paper was to investigate differences in brain structure volumes between schizophrenia and affective psychoses, and whether cumulative lifetime antipsychotic or benzodiazepine doses relate to brain morphology in these groups. We conducted two systematic reviews on the topic and investigated 44 schizophrenia cases and 19 with affective psychoses from the Northern Finland Birth Cohort 1966. The association between lifetime antipsychotic and benzodiazepine dose and brain MRI scans at the age of 43 was investigated using linear regression. Intracranial volume, sex, illness severity, and antipsychotic/benzodiazepine doses were used as covariates. There were no differences between the groups in brain structure volumes. In schizophrenia, after adjusting for benzodiazepine dose and symptoms, a negative association between lifetime antipsychotic dose and the nucleus accumbens volume remained. In affective psychoses, higher lifetime benzodiazepine dose associated with larger volumes of total gray matter and hippocampal volume after controlling for antipsychotic use and symptoms. It seems that in addition to antipsychotics, the severity of symptoms and benzodiazepine dose are also associated with brain structure volumes. These results suggest, that benzodiazepine effects should also be investigated also independently and not only as a confounder.
\end{abstract}

\section{Introduction}

Though affective psychoses are common, they are much less investigated than schizophrenia. They have been considered distinct disease entities with differing aetiology of schizophrenia, though these psychotic disorders also share some similarities. Structural brain changes are found in both individuals with schizophrenia (Hulshoff Pol and Kahn, 2008; Olabi et al., 2011; Vita et al., 2015) and affective psychoses (Bora et al., 2008; Busatto, 2013) when compared to controls. In schizophrenia these changes include both gray and white matter reductions (Olabi et al., 2011), especially in gray matter in the frontal and temporal lobes, hippocampus/amygdala, thalamus and insula (Shepherd et al., 2012). Though similarities can be found in the brain structures in psychotic bipolar disorder compared to schizophrenia, gray matter abnormalities and hippocampal volume reductions are more common in schizophrenia (Bora et al., 2008). Likewise,

\footnotetext{
* Corresponding author at: Center for Life Course Health Research, University of Oulu, Finland.

E-mail address: sanna.huhtaniska@oulu.fi (S. Huhtaniska).
} 
there are abnormalities in brain structures in psychotic depression compared to non-psychotic depression, but less prominently than in schizophrenia (Busatto, 2013).

The current key treatment of psychosis, regardless of its aetiology or the underlying illness, is antipsychotic medication. Suggested harmful effects of high dose long-term antipsychotic treatment on brain structure volumes in psychoses are a debated issue with no consensus (FusarPoli et al., 2013; Huhtaniska et al., 2017a). Gray matter reductions have also been detected in populations at high risk for psychosis (Wood et al., 2008) and drug naïve first episode schizophrenia patients (Leung et al., 2011), which most likely reflects the pathological process leading to illness onset. However, there are some evidence from animal studies that antipsychotic medications affect brain structures even when illness-related factors are not present (Dorph-Petersen et al., 2005; Vernon et al., 2014, 2011). In addition, as the altered morphological findings are not present in all psychotic individuals across diagnoses, it seems that in addition to neurodevelopmental disturbances, environmental factors like medication might additionally contribute to their origin.

According to our previous meta-analysis on long-term antipsychotic effects on brain structures, higher antipsychotic doses associated with decrease in parietal lobe volume and increase in basal ganglia volume (Huhtaniska et al., 2017a). A recent very large cross-sectional study pooling data from over 4000 schizophrenia patients found associations between medication dose and lower cortical thickness in multiple regions, which persisted after controlling for negative symptom severity (van Erp et al 2018). Many previous reviews have included both longitudinal and cross sectional studies. In data supplement table 1 we present previous systematic reviews on cross-sectional studies on antipsychotic medication effects on brain structures in schizophrenia. Based on these, higher doses of antipsychotics have been associated with lower total brain and midbrain volumes, higher doses of typical antipsychotics to lower gray matter, larger basal ganglia, and larger thalamic volumes, and higher doses of atypical antipsychotics to a larger volume of caudate nucleus, thalamus, and hippocampus (Haijma et al., 2013; Navari and Dazzan, 2009; Scherk and Falkai, 2006; Smieskova et al., 2009).

In addition to antipsychotics, individuals with psychosis are often medicated with other psychiatric medications, such as benzodiazepines. When studying medication effects in a non-controlled population, it is important to take into account the possible confounding effects of other medications. To our knowledge, the effect of benzodiazepine use on brain structures has not been studied before in psychoses with the exception of our previous longitudinal study of the Northern Finland Birth Cohort 1966 (NFBC1966) in a smaller sample (Huhtaniska et al., 2017b). Previously benzodiazepine use has been associated with decline in cognition (Baandrup et al., 2017; Fond et al., 2017) and increased mortality (Fontanella et al., 2016) in schizophrenia, and decreased brain plasticity in mice (Curto et al., 2016; Huopaniemi et al., 2004). Therefore, it is interesting to examine, whether there are also effects on brain structures on a macroscopic level.

The naturalistic design of our NFBC1966 data offers an opportunity to study medication effects on brain structures in a population based birth cohort setting during midlife. We are able to analyze data of individuals with psychosis several years after illness onset and several years of treatment. We have previously published longitudinal findings from NFBC1966 follow-up study performed at ages 34 and 43 years for schizophrenia subjects. In these studies, higher doses of antipsychotic medication over the follow-up was associated with a larger total brain volume loss (Veijola et al., 2014), a degree of periventricular brain reduction at the fourth ventricular edge (Guo et al., 2015), and an increase in lateral ventricles after adjusting for symptom severity (Huhtaniska et al., 2017b). Higher benzodiazepine doses during the follow-up was associated with a volume decrease in the caudate nucleus even after controlling for antipsychotic use and illness severity (Huhtaniska et al., 2017b).
In this study, in addition to analysing associations between lifetime antipsychotic and benzodiazepine doses and brain structures in schizophrenia at early midlife, we wanted to investigate and compare whether these medications would also associate with brain structures in a group of individuals with affective psychoses, a group that has been studied considerably less than schizophrenia. First, we systematically reviewed earlier literature on differences in brain morphology between schizophrenia and affective psychoses and findings regarding antipsychotic or benzodiazepine effects on brain structures in affective psychoses. Then, our main aim was to analyse in a general populationbased sample at the age of 43 years, whether there are differences in the brain volumes between schizophrenia and affective psychoses (psychotic depression or psychotic bipolar disorder) and whether lifetime antipsychotic or benzodiazepine doses associate with brain structure volumes when controlling for illness severity measures. The hypotheses were that 1 ) individuals with schizophrenia would show larger ventricular size or smaller volumes of brain structures than individuals with affective psychoses, 2) larger lifetime doses of antipsychotics and benzodiazepines would associate with either larger ventricular size or smaller volumes in brain structures, and 3) the effect of medication would not differ between the groups.

\section{Methods}

\subsection{Systematic reviews}

To systematically review findings on structural differences in the brain between schizophrenia and affective psychoses, a literature search was conducted the 4th of May 2017 from the database of PubMed. We used the search terms: psychotic and (bipolar or depressive or depression) and MRI and brain, and the search was directed to human studies only. Inclusion criteria were cross-sectional design and brain volume comparisons were made between any affective psychosis group and schizophrenia. Only studies comparing two groups with a history of psychosis were included.

To examine previous findings regarding antipsychotic and benzodiazepine use and brain structures in affective psychoses, a literature search was conducted the 4th of May 2017 from the database of PubMed. We used the search terms: psychotic and (bipolar or depressive or depression or affective) and (antipsychotic or benzodiazepine) and MRI and brain and (structure or structural or morphometry), and the search was directed to human studies only. In addition, we screened previous reviews on topic, references of included studies and all the included studies from the previously described search regarding differences between brain structures in schizophrenia and affective psychoses. Inclusion criteria was that the association between antipsychotic or benzodiazepine medication and brain structures was examined in any sample of affective psychosis.

\subsection{Sample of NFBC1966}

The participants of this study were members of the Northern Finland Birth Cohort 1966 (NFBC1966), which is an unselected, general population birth cohort identified during mid-pregnancy based on an expected delivery date during 1966 in the provinces of Lapland and Oulu, Finland. The cohort has been described in more detail in previous publications (Husa et al., 2017; Nykänen et al., 2016). Permission to gather data was obtained from the Ministry of Social and Health Affairs and the study design was approved by the Ethical Committee of the Northern Ostrobothnia Hospital District.

This study is based on 63 individuals with psychosis from the NFBC1966, who participated in the brain MRI scan, psychiatric interviews and examinations in 2008-2011, at an average age of 43 years (SD 0.8), and had adequate structural MRI scans. Diagnoses were based on information from national registers, hospital notes and SCID-I interview (First et al., 2002) performed during the study at the age 43 
years (hereafter "43-year study"). The sample included 44 cases with schizophrenia (including 2 cases with schizophreniform disorder), and 19 cases with affective psychosis (including 6 cases with bipolar psychosis and 13 with psychotic depression). Written informed consent was obtained from all participants and the participants have the possibility to deny the use of their data at any time.

\subsubsection{Data on use of psychiatric medication}

Information on lifetime use of psychiatric medications, until the day the person was examined in the 43-year study, was gathered by a careful review of individual hospital, outpatient and health centre notes of all cases from everywhere in Finland. This procedure is described in more detail in previous publications from the NFBC1966 (Husa et al., 2014; Moilanen et al., 2015). Current and earlier use of psychiatric medications and their doses were ascertained in the interview at 43year study by asking about the use of psychiatric medications during the previous 3 months and as far as the subjects could remember.

All medical records were reviewed to record the name of the drug, dose and period the medication had been used. Drugs were categorized by using the Anatomical Therapeutic Chemical (ATC) classification system (WHO 2011). Antipsychotics included classes N05A (antipsychotics) and N06CA01 (combination medicine including perphenazine). Benzodiazepines included classes N05BA (anxiolytics, benzodiazepine derivatives), N05CD (hypnotics and sedatives, benzodiazepine derivatives), and N05CF (hypnotics and sedatives, benzodiazepine-related drugs). The information was used to calculate the cumulative dose of lifetime medication in defined daily doses (DDD) and these were then expressed as dose-years. One DDD year (DDDy) is equivalent to using one DDD daily for a year.

\subsubsection{Covariates}

As a marker of illness severity, we used Positive and Negative Syndrome Scale (PANSS) (Kay et al., 1987), which was assessed at the 43-year study using a specific interview. The age at onset of the illness was ascertained from medical records and it was defined as the age of first evident psychotic symptoms. Due to the birth cohort design, age of illness onset also reflects duration of illness. Sex and intracranial volume (ICV) were used as additional covariates.

\subsubsection{Imaging data}

The participants were scanned with the same 1.5 T GE Signa scanner (General Electric, Milwaukee, Wisconsin) at the Oulu University Hospital at the 43-year study. T1 weighted images were acquired with a 3D fast spoiled gradient echo (FSPGR) sequence (slice thickness $=1 \mathrm{~mm}$; in-plane resolution matrix size $256 \times 256$; voxel size $1 \mathrm{~mm}^{3}$; repetition time $12.576 \mathrm{~ms}$; echo time $5.3 \mathrm{~ms}$; flip angle $=20^{\circ}$ ).

To extract the brain structure volumes from the MRI images we used an online automated MRI brain volumetry system volBrain (http:// volbrain.upv.es/) (Manjón and Coupé, 2016). Based on previously reported reliability measures (Huhtaniska et al., 2017b) and previous brain imaging findings in psychoses, we selected 10 brain areas to be examined: total brain, total gray matter (GM), cerebrum, cerebral GM, lateral ventricles, caudate, putamen, thalamus, hippocampus, accumbens). Details on the reliability measures and image processing pipeline are described in our previous publication (Huhtaniska et al., 2017b) and briefly in supplementary material.

\subsubsection{Statistical analyses}

Independent samples t-test was used to assess the differences between the background variables of the groups. Differences between brain areas of subjects with schizophrenia and affective psychoses and associations between lifetime and medication doses and brain areas were analysed in both groups. A logarithmic transformation was applied to medication data because of the skewness of the variables and these were used as continuous variables in analyses. All confounders were analysed as continuous variables.
We used several models to investigate the associations between lifetime medication doses and brain structures in both groups. All analyses were made using linear regression with sex and intracranial volume (ICV) as covariates. The medication analyses were additionally adjusted for PANSS total score and onset age. Benzodiazepine DDDy were added as a covariate in analyses of antipsychotic DDDy, and vice versa. In addition, we analysed the group $\mathrm{x}$ medication interactions in models, where in addition to ICV, sex, group and medication dose we included the interaction term group $\mathrm{x}$ medication. Corrections for multiple comparisons were made using the Benjamini-Hochberg procedure with $10 \%$ False Discovery Rate. The analyses were performed using IBM SPSS Statistics version 23 using $p<0.05$ as a limit for statistical significance.

\section{Results}

\subsection{Systematic reviews}

\subsubsection{Differences in brain structures between schizophrenia and affective psychoses}

The search located 291 studies and after abstract and title review 94 articles were evaluated in detail. The final number of included studies was 30. The data collection in presented in data supplement Fig 1 and detailed information on included studies are presented in data supplement Table 2

Of the found 30 studies, 15 examined differences between schizophrenia and psychotic bipolar disorder cases. Only six studies investigated differences between mixed mood disorder group and schizophrenia and only two studies differences between psychotic depression and schizophrenia. A summary of the findings of the review is presented in Table 1 . In the studies with statistically significant findings, the cortical volumes were smaller in the schizophrenia group compared to affective psychoses groups, and the only findings with larger volumes in schizophrenia were found in putamen, caudate and globus pallidus when compared to psychotic bipolar disorder (Mamah et al., 2016; Rimol et al., 2010). Regarding lateral ventricles, the size was larger in schizophrenia than in psychotic bipolar disorder (McDonald et al., 2006), but larger in psychotic depression than in schizophrenia (Salokangas et al., 2002). Of the found 30 studies, 9 did not find any differences between these groups in their regions of interest (Cui et al., 2011; Janssen et al., 2014; Koo et al., 2008; Morgan et al., 2007; Radonic et al., 2008; Reite et al., 2010; Rosa et al., 2010; Rosa et al., 2015; Strasser et al., 2005).

3.1.2. Associations between antipsychotic and benzodiazepine use and brain volumes in affective psychoses

The search located 18 studies, of which 8 fulfilled our inclusion criteria. In addition, 63 full text articles from other sources were investigated. In total, 71 articles were assessed in detail, and 15 studies were included in the systematic review. The data collection is described in data supplement Fig. 2 and detailed information on all included studies in data supplement Table 3 .

Of the 15 included studies, the majority did not find associations between medication and brain structures. Six studies investigated antipsychotic dose effects on brain structures, and seven studies antipsychotic status or exposure (yes/no), but none of these found any associations. Instead, two out of four studies investigating antipsychotic treatment duration found an association between longer duration and morphological differences: one found an association between antipsychotics and positive vertex displacement in right pallidum in psychotic bipolar disorder (Liberg et al., 2015), and another between longer duration of antipsychotic exposure and increased ventricular volumes in affective psychoses but not in schizophrenia (Morgan et al., 2007). A summary of the findings of the review is presented in Table 2. 
Table 1

Summary of the findings in schizophrenia based on the systematic review of differences in brain volumes between schizophrenia and affective psychoses.

\begin{tabular}{|c|c|}
\hline Finding & Studies \\
\hline \multicolumn{2}{|l|}{$\begin{array}{l}\text { Statistically significant findings between schizophrenia and psychotic bipolar } \\
\text { disorder: }\end{array}$} \\
\hline - Smaller volumes in cerebellum & Ivleva et al., 2012; Ivleva et al., 2013 \\
\hline - Gray matter deficits in cerebellum & Nenadic et al., 2015b \\
\hline - Widespread cortical and subcortical gray matter volume reductions & $\begin{array}{l}\text { Brown et al., 2011; Ivleva et al., 2012; Ivleva et al., 2013; Mamah et al., 2016; } \\
\text { McDonald et al., 2005; Nenadic et al., 2015a, b; Salokangas et al., 2002; Harvey et al., } \\
1994\end{array}$ \\
\hline - Smaller cerebral gray matter volume & Harvey et al., 1994 \\
\hline - Smaller total gray matter volume & Mamah et al., 2016 \\
\hline - Smaller gray matter volume in subgenual cortex & Yüksel et al., 2012 \\
\hline - Smaller hippocampal volumes & $\begin{array}{l}\text { Arnold et al., 2015; McDonald et al., 2006; Radonic et al., 2011; GM: Brown et al., } \\
\text { 2011; Nenadic et al., 2015a, b }\end{array}$ \\
\hline - Larger volume of putamen & Mamah et al., 2016; RImol et al., 2010 \\
\hline - Smaller volume of putamen & Brown et al., 2011 \\
\hline - Different shape of amygdala & Mahon et al., 2015 \\
\hline - Smaller amygdala & Mahon et al., 2012 \\
\hline - Smaller gray matter volume in amygdala & Brown et al., 2011 \\
\hline - Larger volumes of caudate and globus pallidus & Mamah et al., 2016 \\
\hline - Larger ventricle volumes & Mc Donald et al., 2006 \\
\hline \multicolumn{2}{|l|}{$\begin{array}{l}\text { Statistically significant findings between schizophrenia and schizoaffective } \\
\text { disorder }\end{array}$} \\
\hline $\begin{array}{l}\text { - Smaller gray matter volumes in frontotemporal, cingulate, parietal and occipital } \\
\text { cortices }\end{array}$ & Ivleva et al., 2012 \\
\hline \multicolumn{2}{|l|}{ Statistically significant findings between schizophrenia and psychotic depression } \\
\hline - Smaller volume in left posterior subgenual cortex & Coryel et al., 2005 \\
\hline - Smaller ventricular CSF volumes & Salokangas et al., 2002 \\
\hline \multicolumn{2}{|l|}{$\begin{array}{l}\text { Statistically significant findings between schizophrenia and combined affective } \\
\text { psychoses group }\end{array}$} \\
\hline - Smaller total brain and total gray matter volumes & El-Sayed et al., 2010 \\
\hline - Smaller insular gray matter volume & Kasai et al., 2003 \\
\hline - Higher rate of cavum septum pellucidum & Jurjus et al., 1993 \\
\hline \multicolumn{2}{|l|}{ No differences between schizophrenia and psychotic bipolar disorder } \\
\hline - Gray matter VBM & Cui et al., 2011 \\
\hline - Lobar cortical thickness, surface are, gyrification index and sulcal width & Janssen et al., 2014 \\
\hline - Intracranial volume, white matter volume, nucleus accumbens and thalamic volumes & Mamah et al., 2016 \\
\hline - Cerebral volume & Mc Donald et al., 2006 \\
\hline - Temporal lobe volume and asymmetry & Radonic et al., 2008 \\
\hline - Superior temporal gyrus laminar thickness & Ratnanather et al., 2013 \\
\hline - Lateral ventricles & Rosa et al., 2010 \\
\hline $\begin{array}{l}\text { - Cortical thickness, hippocampus, amygdala, thalamus, ventricles, nucleus accumbens, } \\
\text { ventral diencephalon, cerebellar cortex or white matter, caudate, pallidum or } \\
\text { brainstem }\end{array}$ & Rimol et al., 2010 \\
\hline - Left hippocampus, lateral ventricles & Strasser et al., 2005 \\
\hline \multicolumn{2}{|l|}{ No differences between schizophrenia and schizoaffective disorder } \\
\hline - gray matter VBM & Ivleva et al., 2013 \\
\hline - Intracerebral volume, total brain volume, ventricular volume & Reite et al., 2010 \\
\hline - Temporal lobe volume and asymmetry & Radonic et al., 2008 \\
\hline \multicolumn{2}{|l|}{ No differences between schizophrenia and combined affective psychoses group } \\
\hline - Frontal lobes, superior temporal cortices, hippocampus, insula, whole brain VBM & Rosa et al., 2015 \\
\hline - Temporal pole gray matter volume & Kasai et al., 2003 \\
\hline - VBM & Morgan et al., 2007 \\
\hline $\begin{array}{l}\text { - Cingulate gyrus gray matter volumes in } 3 \text { anterior subregions and } 1 \text { posterior } \\
\text { subregion }\end{array}$ & Koo et al., 2008 \\
\hline
\end{tabular}

VBM $=$ voxel-based morphometry

\subsection{The NFBC1966 study}

\subsubsection{Characteristics of the sample}

The characteristics of the sample are described in Table 3. The schizophrenia group included more males (61\%) than the affective psychoses group (32\%). Only $10 \%$ of the schizophrenia group were married/cohabited compared to the $53 \%$ in affective psychoses group. The PANSS total and subscores were higher in the schizophrenia group

Table 2

Summary of the systematic review of associations between medication and brain volumes in affective psychoses.

\begin{tabular}{|c|c|}
\hline Finding & Studies \\
\hline $\begin{array}{l}\text { - Longer duration of antipsychotic exposure correlated with increased third } \\
\text { ventricle and lateral ventricle volumes in affective psychoses group }\end{array}$ & Morgan et al., 2007 \\
\hline $\begin{array}{l}\text { - Significant association between antipsychotics and positive vertex } \\
\text { displacement in the right pallidum in psychotic bipolar disorder }\end{array}$ & Liberg et al., 2015 \\
\hline $\begin{array}{l}\text { - No association between antipsychotic medication and investigated brain } \\
\text { volumes }\end{array}$ & $\begin{array}{l}\text { Arnold et al., 2015; Giakoumatos et al., 2015; Ivleva et al., 2012; Ivleva et al., 2013; Janssen } \\
\text { et al., 2014; Kasai et al., 2003; Koo et al., 2008; Mathew et al., 2014; Rimol et al., 2010; Rosa } \\
\text { et al., 2010; Strakowski et al., 1999; Woodward and Heckers 2015; Yüksel et al., } 2012\end{array}$ \\
\hline
\end{tabular}


Table 3

Characteristics of the sample.

\begin{tabular}{|c|c|c|}
\hline & $\begin{array}{l}\text { Schizophrenia } \\
(N=44)\end{array}$ & $\begin{array}{l}\text { Affective psychoses } \\
(N=19)\end{array}$ \\
\hline \multicolumn{3}{|l|}{ Gender* $N(\%)$} \\
\hline Male & $27(61)$ & $6(32)$ \\
\hline \multicolumn{3}{|l|}{ Age at the study moment, years } \\
\hline Mean age (SD), range & $43.1(0.7), 41.8-44.5$ & $\begin{array}{l}43.7(0.6) \\
41.9-44.4\end{array}$ \\
\hline \multicolumn{3}{|l|}{$\begin{array}{l}\text { Marital status at the study } \\
\text { moment }^{*} N(\%)\end{array}$} \\
\hline Married or cohabiting & $10(23)$ & $10(53)$ \\
\hline Single & $34(77)$ & $9(47)$ \\
\hline \multicolumn{3}{|l|}{$\begin{array}{l}\text { Educational level at the study } \\
\text { moment } N(\%)\end{array}$} \\
\hline Low & $24(55)$ & $12(63)$ \\
\hline Middle & $10(23)$ & $4(21)$ \\
\hline High & $10(23)$ & $3(16)$ \\
\hline \multicolumn{3}{|l|}{$\begin{array}{l}\text { Work status at the study } \\
\text { moment } N(\%)\end{array}$} \\
\hline Disability pension & $26(60)$ & $9(47)$ \\
\hline Employed & $12(27)$ & $7(37)$ \\
\hline Other $^{\mathrm{a}}$ & $5(11)$ & $2(11)$ \\
\hline Current alcohol abuse $N(\%)$ & $4(9)$ & $4(21)$ \\
\hline \multicolumn{3}{|l|}{ Diagnosis $N(\%)$} \\
\hline Schizophrenia & $42(96)$ & \\
\hline Schizophreniform disorder & $2(4)$ & \\
\hline Psychotic bipolar disorder & & $6(32)$ \\
\hline Psychotic depression & & $13(68)$ \\
\hline \multicolumn{3}{|l|}{$\begin{array}{l}\text { Lifetime hospital treatment } \\
\text { days }{ }^{*}\end{array}$} \\
\hline Mean (SD) median, range & $\begin{array}{l}579(899) 213 \\
1-5093\end{array}$ & $\begin{array}{l}146(124), 93 \\
2-399\end{array}$ \\
\hline \multicolumn{3}{|l|}{$\begin{array}{l}\text { PANSS mean (SD) median, } \\
\text { range }\end{array}$} \\
\hline Total symptoms score* & 70 (27), 26, 30-130 & 43 (11), 42, 31-75 \\
\hline Positive symptoms score ${ }^{*}$ & 17 (8) $16,6-32$ & $9(3), 8,4-16$ \\
\hline Negative symptoms score* & 19 (10) $17,8-43$ & $12(4), 9,8-21$ \\
\hline Emotional symptoms score* & $18(7) 16,8-33$ & $12(4), 10,8-19$ \\
\hline Excitement symptoms score* & 15 (5) $14,8-29$ & $10(2), 10,8-14$ \\
\hline Disorganized symptoms score* & 25 (12) $23,10-59$ & 15 (7), 13, 9-36 \\
\hline Remission* $N(\%)$ & $11(25)$ & $17(90)$ \\
\hline Onset age* mean (SD), Range & 25 (6.3), 16.7-42.0 & 33 (5.9), 21.4-41.2 \\
\hline
\end{tabular}

PANSS $=$ Positive And Negative Syndrome Scale, DDD = defined daily dose. The cumulative number of hospital days since illness onset until the 43-years study was collected from the Care Register for Health Care. Remission was assessed using the remission criteria by Andreasen et al. (2005), and based on PANSS interview. The symptoms were only required not to be present during the period of one week before the assessment, and no duration criteria was used since PANSS was done only once.

${ }^{\text {a }}$ Unemployed or not in working life due to other reasons than disability pension.

* Statistically significant differences between the groups.

and fewer individuals were in remission $(21 \%)$ than in the affective psychoses group (90\%). The onset age was significantly lower in the schizophrenia group compared to the affective psychoses group. However, there were no significant differences in educational level or the number of people on disability pension between the groups.

There were no statistically significant differences between brain volumes of the two groups in any studied brain areas, see data supplement Table 4.1 for details.

\subsubsection{Characteristics of lifetime medication use}

The characteristics of medication use in the sample are presented in Table 4. In the schizophrenia group 42 (96\%) individuals had used antipsychotics during lifetime, and the cumulative mean dose was 20.1 DDDy. Thirty-nine (88\%) individuals had used typical and 35 (80\%) individuals atypical antipsychotics. Thirty-three (75\%) individuals had used benzodiazepines (mean dose 9.1 DDDy). Thirty-two (73\%) individuals had used both antipsychotics and benzodiazepines. In the affective psychoses group 15 (79\%) individuals had used antipsychotics
Table 4

Number of persons using antipsychotics and benzodiazepines during their lifetime and lifetime doses of medication.

\begin{tabular}{|c|c|c|}
\hline & $\begin{array}{l}\text { Schizophrenia }(N=44) \\
N\left(\%{ }^{\mathrm{a}}\right) \text {, mean DDDy } \\
(\mathrm{SD})\end{array}$ & $\begin{array}{l}\text { Affective } \\
\text { psychoses } \\
(N=19) \\
N\left(\%^{\mathrm{a}}\right), \text { mean } \\
\text { DDDy (SD) }\end{array}$ \\
\hline \multicolumn{3}{|l|}{ Use of antipsychotics in DDDy } \\
\hline Use of antipsychotics & 42 (96), $20.1(20.5)$ & 15 (79), 3.8 (4.4) \\
\hline Use of typical antipsychotics & 39 (88), $11.3(14.9)$ & $11(58), 1.0(1.0)$ \\
\hline Use of atypical antipsychotics & $35(80), 11.5(9.4)$ & $11(58), 4.2(4.3)$ \\
\hline \multicolumn{3}{|l|}{$\begin{array}{l}\text { Use of benzodiazepines in } \\
\text { DDDy }\end{array}$} \\
\hline Use of benzodiazepines & $33(75) 9.1(10.5)$ & $6(32), 5.8(8.2)$ \\
\hline $\begin{array}{l}\text { Use of benzodiazepines only } \\
\text { irregularly }\end{array}$ & $5(11)$ & $1(5)$ \\
\hline $\begin{array}{l}\text { Use of both antipsychotics and } \\
\text { benzodiazepines }\end{array}$ & $\begin{array}{l}32 \text { (73), ap } 23.5(22.4) \text {, } \\
\text { bzd } 9.4(10.6)\end{array}$ & $\begin{array}{l}5(26) \text {, ap } 5.2 \\
(6.8), \text { bzd } 6.6(8.9)\end{array}$ \\
\hline
\end{tabular}

$N=$ number of cases, SD = standard deviation, DDDy $=$ dose years in defined daily dose, ap = antipsychotic, bzd = benzodiazepine.

a The percentage of cases that have had the medication at any point of their illness.

(mean dose 3.8 DDDy). Eleven (58\%) individuals had used typical and $11(58 \%)$ individuals atypical antipsychotics. Six (32\%) individuals had used benzodiazepines (mean dose 5.8 DDDy). Five (26\%) had used both benzodiazepines and antipsychotics. All the used medications are listed in data supplement Table 5. Many of the study subjects had used several different antipsychotics during their lifetime, especially those with schizophrenia.

\subsubsection{Association between lifetime cumulative antipsychotic doses and brain volumes}

In schizophrenia, higher cumulative lifetime antipsychotic doses were associated with brain volumes in several areas (see data supplement table 6 for details), and after adjusting the analyses for benzodiazepine use (see Table 5), the associations remained in total GM ( $b=-0.25, p=0.017)$, cerebral GM $(b=-0.25 p=0.024)$, thalamus $(b=-0.39 p=0.014)$ and nucleus accumbens $(b=-0.40$, $p=0.014)$. When correcting for multiple comparisons, all the associations remained. When further examining subcortical volumes, the associations were similar in both hemispheres with the exception of the association between antipsychotic use and right lateral ventricle volume (see supplement Table 4.2 for details). After adding onset age to the model, the statistically significant associations still remained in total GM $(\mathrm{b}=-0.26, p=0.025)$, cerebral GM $(\mathrm{b}=-0.29$, $p=0.019)$, thalamus $(\mathrm{b}=-0.42, p=0.016)$, nucleus accumbens ( $b=-0.46, p=0.011)$, and the lateral ventricles $(b=0.39$, $p=0.046)$ and all associations remained except the one in lateral ventricles after correcting for multiple comparisons. When replacing onset age with PANSS total score as a marker of illness severity, only the association in nucleus accumbens remained $(\mathrm{b}=-0.38$, $p=0.033$ ) statistically significant, though the finding in thalamus almost reached significance as well $(\mathrm{b}=-0.34, p=0.050)$. However, in the PANSS adjusted analyses, PANSS total score did not either associate to the structure volumes with the exception of lateral ventricles ( $b=0.43, p=0.018$ ), which did not remain after the correction for multiple comparisons. The results of the analyses are presented in Table 5 and the results of further adjusted analyses in Table 6.

There were no statistically significant associations between lifetime antipsychotic doses and volumes of brain structures in affective psychoses (Tables 5 and 6, data supplement Table 6).

3.2.4. Association between lifetime cumulative benzodiazepine dose and brain volumes

In schizophrenia higher lifetime benzodiazepine doses associated 
Table 5

Association between antipsychotic DDDy, benzodiazepine DDDy and brain volumes in the same model separately in schizophrenia and affective psychoses. Sex and ICV as covariates in all analyses. Statistically significant findings in bold.

\begin{tabular}{|c|c|c|c|c|c|}
\hline \multirow{3}{*}{ Brain area } & & \multicolumn{4}{|c|}{ Antipsychotic dose and benzodiazepine in the same model } \\
\hline & & \multicolumn{2}{|l|}{$\begin{array}{l}\text { Schizophrenia } \\
(N=44)\end{array}$} & \multirow[t]{2}{*}{$\begin{array}{l}\text { Affective } \\
\text { psychoses } \\
(N=19) \\
\text { b }\end{array}$} & \multirow[b]{2}{*}{$p$} \\
\hline & & $\mathrm{b}$ & $p$ & & \\
\hline \multirow[t]{2}{*}{ Total Brain } & ap & -0.128 & 0.118 & 0.067 & 0.526 \\
\hline & bzd & -0.154 & 0.062 & 0.190 & 0.081 \\
\hline \multirow[t]{2}{*}{ Total GM } & ap & -0.251 & $0.017^{*}$ & 0.108 & 0.412 \\
\hline & bzd & 0.028 & 0.786 & 0.328 & $0.021 *$ \\
\hline \multirow[t]{2}{*}{ Cerebrum } & ap & -0.134 & 0.125 & 0.086 & 0.384 \\
\hline & bzd & -0.138 & 0.115 & 0.233 & 0.028 \\
\hline \multirow[t]{2}{*}{ Cerebrum GM } & ap & -0.247 & $0.024 *$ & 0.132 & 0.306 \\
\hline & bzd & 0.044 & 0.682 & 0.314 & $0.023 *$ \\
\hline \multirow[t]{2}{*}{ Lateral ventricles } & ap & 0.325 & 0.061 & 0.027 & 0.913 \\
\hline & bzd & 0.064 & 0.699 & -0.358 & 0.163 \\
\hline \multirow[t]{2}{*}{ Caudate } & ap & 0.002 & 0.990 & 0.373 & 0.081 \\
\hline & bzd & 0.121 & 0.471 & 0.201 & 0.324 \\
\hline \multirow[t]{2}{*}{ Putamen } & ap & 0.169 & 0.282 & 0.122 & 0.605 \\
\hline & bzd & 0.004 & 0.980 & 0.214 & 0.365 \\
\hline \multirow[t]{2}{*}{ Thalamus } & ap & -0.387 & $0.014 *$ & -0.176 & 0.345 \\
\hline & bzd & 0.005 & 0.971 & 0.458 & $0.022 *$ \\
\hline \multirow[t]{2}{*}{ Hippocampus } & ap & -0.255 & 0.113 & -0.046 & 0.766 \\
\hline & bzd & -0.077 & 0.627 & 0.563 & $0.002^{*}$ \\
\hline \multirow[t]{2}{*}{ Accumbens } & ap & -0.396 & $0.014^{*}$ & 0.108 & 0.589 \\
\hline & bzd & 0.134 & 0.390 & -0.055 & 0.779 \\
\hline
\end{tabular}

ICV = intracranial volume, $\mathrm{b}=$ standardized beta, ap = antipsychotic, bzd = benzodiazepine.

* Statistically significant $(p<0.05)$ after Benjamini-Hochberg correction.

with lower volumes of total brain $(b=-0.23, p=0.002)$ and cerebrum $(b=-0.21, p=0.006)$. After adjusting the analysis for antipsychotic doses, no associations remained. When onset age was added to the model, there was again a significant association between higher benzodiazepine doses and lower volume of total brain $(b=-0.17$, $p=0.044)$, but this association did not remain when adjusting for PANSS total score instead of onset age (Tables 5 and 6, data supplement Table 7).

In affective psychoses, higher lifetime doses of benzodiazepines were associated with larger volumes in the cerebrum $(b=0.23$, $p=0.028)$, total GM ( $\mathrm{b}=0.33, p=0.021)$, cerebral GM $(\mathrm{b}=0.31$, $p=0.023)$, thalamus ( $\mathrm{b}=0.46, p=0.022)$ and hippocampus ( $b=0.56, p=0.002$ ) after adjusting for lifetime antipsychotic doses. After correcting for multiple comparisons all associations remained except the one in cerebrum. When further examining subcortical volumes, the associations were similar in both hemispheres (see supplement Table 4.2 for details). After additional adjusting with onset age, all the above mentioned associations remained. However, when adjusting for PANSS total score instead of onset age, only the associations in total GM ( $\mathrm{b}=0.28, p=0.045)$ and hippocampus $(\mathrm{b}=0.48$, $p=0.007$ ) remained. Both of these results survived the correction for multiple comparisons. All results are presented in Tables 5 and 6 and data supplement Table 7.

\subsubsection{Interaction analyses}

There were statistically significant associations between group $\times$ antipsychotic interaction and brain volumes in total GM and cerebral GM. In the group $\times$ benzodiazepine interaction analyses there were statistically significant findings in total brain, total GM, cerebrum, cerebral GM, thalamus and hippocampus. In all these findings, there was a negative association in schizophrenia but positive in affective psychoses. All interaction analysis results are presented in data supplement Tables 6 and 7.

\section{Discussion}

\subsection{Main results}

Based on the systematic review, the differences in brain structures between schizophrenia and affective psychoses are not clear, since there are both studies reporting differences and no differences. The differences are reported mainly in gray matter volumes and basal ganglia structures.

There are no previous studies on the association between benzodiazepine use and brain structures in affective psychoses, and of the studies focusing on the association between antipsychotic use and brain structures, there were only two statistically significant findings.

Our first hypothesis was not supported by the results, since we found no differences in brain structure volumes at the age of 43 years between the two diagnostic groups, even though onset age (which corresponds to duration of illness in this sample) and illness severity (PANSS total score) were significantly different between the groups. Likewise, many earlier studies have also found no differences (Table 1).

The second hypothesis was partly supported by the results, since in the schizophrenia group, higher cumulative lifetime antipsychotic doses associated with smaller volumes of several areas; after adding PANSS total score to the model, the association in nucleus accumbens still remained, and the association in thalamus almost reached significance. Higher cumulative doses of benzodiazepines associated with smaller volumes of total brain after controlling for antipsychotic doses and onset age (i.e. illness duration), but the association did not remain when adjusted for PANSS total score instead of onset age.

However, in the affective psychoses group, the second hypothesis was not supported by the results, since there were no associations between lifetime antipsychotic doses and volumes of brain structures. Surprisingly, higher lifetime doses of benzodiazepines associated with larger volumes in total GM and hippocampus after controlling for antipsychotic dose and PANSS total score. Since the results were different in between the patient groups, as indicated by interaction analyses, our third hypotheses was not supported by the results.

\subsection{Antipsychotic use and brain volumes}

In previous studies of an overlapping NFBC1966 sample, a higher amount of antipsychotic medication predicted total brain volume loss (Veijola et al., 2014) and lateral ventricular volume increase (Huhtaniska et al., 2017b; Veijola et al., 2014), as well as periventricular brain volume reductions at the fourth ventricular edge (Guo et al., 2015) over a 9-year follow-up. In addition to brain findings, higher doses of antipsychotics associated with decline in verbal learning and memory (Husa et al., 2014), and high lifetime doses and antipsychotic polypharmacy associated with poorer outcomes in schizophrenia in the NFBC1966 (Moilanen et al., 2016). These previous findings and the findings of this study are somewhat consistent and suggest that high-dose long-term antipsychotic medications may have some non-profitable effects on the brain in schizophrenia.

Our results regarding the association of antipsychotics and lower gray matter volumes in schizophrenia are in line with the previous review of Haijma et al. (2013). However, the findings regarding associations between antipsychotic doses and smaller volumes in thalamus and nucleus accumbens in schizophrenia have not been reported by previous reviews, but instead they have reported larger volumes of the thalamus and basal ganglia (Navari and Dazzan, 2009; Scherck and Falkai, 2006; Smieskova et al., 2009).

Though the associations between higher lifetime doses of antipsychotics and brain structures in schizophrenia were confounded by PANSS total score, the overall estimates of the models including PANSS, sex, and ICV and antipsychotic dose, sex, and ICV were of the same magnitude (see data supplement Table 8). Therefore, it seems, that antipsychotics, benzodiazepines, age of illness onset or duration of 
Table 6

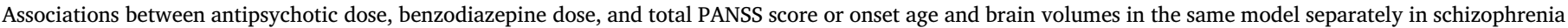
and affective psychoses. Sex and ICV as covariates in all analyses. Statistically significant findings in bold.

\begin{tabular}{|c|c|c|c|c|c|}
\hline \multirow[b]{2}{*}{ Brain area } & & \multicolumn{2}{|c|}{ Antipsychotic dose, benzodiazepine dose and PANSS in the same model } & \multicolumn{2}{|c|}{$\begin{array}{l}\text { Antipsychotic dose, benzodiazepine dose and onset age in the same } \\
\text { model }\end{array}$} \\
\hline & & Schizophrenia $(N=44)$ & Affective psychoses $(N=19)$ & Schizophrenia $(N=44)$ & Affective psychoses $(N=19)$ \\
\hline \multirow[t]{3}{*}{ Total Brain } & AP & $\mathrm{b}=-0.078 p=0.387$ & $\mathrm{~b}=0.181 p=0.178$ & $\mathrm{~b}=-0.165 p=0.070$ & $\mathrm{~b}=0.057 p=0.595$ \\
\hline & BZD & $\mathrm{b}=-0.113 p=0.204$ & $\mathrm{~b}=0.147 p=0.173$ & $\mathrm{~b}=-0.171 p=0.044$ & $\mathrm{~b}=0.209 p=0.070$ \\
\hline & $\begin{array}{l}\text { PANSS/onset } \\
\text { age }\end{array}$ & $\mathrm{b}=-0.127 p=0.163$ & $-\mathrm{b}=0.195 p=0.143$ & $\mathrm{~B}=-0.082 p=0.334$ & $\mathrm{~b}=0.092 p=0.469$ \\
\hline \multirow[t]{3}{*}{ Total GM } & AP & $\mathrm{b}=-0.171 p=0.120$ & $\mathrm{~b}=0.265 p=0.119$ & $\mathrm{~b}=-0.263 p=0.025^{*}$ & $\mathrm{~b}=0.098 p=0.470$ \\
\hline & BZD & $\mathrm{b}=0.079 p=0.453$ & $\mathrm{~b}=0.283 p=0.045^{*}$ & $\mathrm{~b}=0.022 p=0.831$ & $\mathrm{~b}=0.349 p=0.021 *$ \\
\hline & $\begin{array}{l}\text { PANSS/onset } \\
\text { age }\end{array}$ & $\mathrm{b}=-0.202 p==0.066$ & $-\mathrm{b}=0.259 p=0.120$ & $\mathrm{~b}=-0.026 p=0.808$ & $\mathrm{~b}=0.101 p=0.524$ \\
\hline \multirow[t]{3}{*}{ Cerebrum } & AP & $\mathrm{b}=-0.073 p=0.445$ & $\mathrm{~b}=0.179 p=0.165$ & $\mathrm{~b}=-0.183 p=0.060$ & $\mathrm{~b}=0.080 p=0.437$ \\
\hline & BZD & $\mathrm{b}=-0.091 p=0.329$ & $\mathrm{~b}=0.202 p=0.059$ & $\mathrm{~b}=-0.160 p=0.075$ & $\mathrm{~b}=0.246 p=0.029^{*}$ \\
\hline & $\begin{array}{l}\text { PANSS/onset } \\
\text { age }\end{array}$ & $\mathrm{b}=-0.157 p=0.104$ & $-\mathrm{b}=0.157 p=0.211$ & $\mathrm{~b}=-0.107=0.237$ & $\mathrm{~b}=0.065 p=0.588$ \\
\hline \multirow[t]{3}{*}{ Cerebrum GM } & $\mathrm{AP}$ & $\mathrm{b}=-0.159 p=0.157$ & $\mathrm{~b}=0.274 p=0.117$ & $b=-0.286 p=0.019^{*}$ & $\mathrm{~b}=0.128 p=0.342$ \\
\hline & BZD & $\mathrm{b}=0.097 p=0.375$ & $\mathrm{~b}=0.270 p=0.060$ & $\mathrm{~b}=0.027 \mathrm{p}=0.808$ & $\mathbf{b}=0.322 p=0.029^{*}$ \\
\hline & $\begin{array}{l}\text { PANSS/onset } \\
\text { age }\end{array}$ & $\mathrm{b}=-0.221 p=0.052$ & $-\mathrm{b}=0.229 p=0.177$ & $\mathrm{~b}=-0.085 \mathrm{p}=0.444$ & $\mathrm{~b}=0.041 p=0.790$ \\
\hline \multirow[t]{3}{*}{ Lateral ventricles } & $\mathrm{AP}$ & $\mathrm{b}=0.160 p=0.363$ & $-\mathrm{b}=0.212 p=0.526$ & $\mathrm{~b}=0.388 p=0.046$ & $\mathrm{~b}=0.045 p=0.860$ \\
\hline & BZD & $\mathrm{b}=-0.060 p=0.725$ & $-\mathrm{b}=0.271 p=0.317$ & $\mathrm{~b}=0.069 p=0.692$ & $-\mathrm{b}=0.394 p=0.148$ \\
\hline & $\begin{array}{l}\text { PANSS/onset } \\
\text { age }\end{array}$ & $\mathrm{b}=0.432 p=0.018$ & $\mathrm{~b}=0.443 p=0.189$ & $\mathrm{~b}=0.137 p=0.444$ & $-\mathrm{b}=0.176 p=0.563$ \\
\hline \multirow[t]{3}{*}{ Caudate } & $\mathrm{AP}$ & $\mathrm{b}=0.031 p=0.867$ & $\mathrm{~b}=0.537 p=0.074$ & $\mathrm{~b}=-0.078 p=0.674$ & $\mathrm{~b}=0.344 p=0.103$ \\
\hline & BZD & $\mathrm{b}=0.157 p=0.391$ & $\mathrm{~b}=0.140 p=0.536$ & $\mathrm{~b}=0.086 p=0.614$ & $\mathrm{~b}=0.259 p=0.214$ \\
\hline & $\begin{array}{l}\text { PANSS/onset } \\
\text { age }\end{array}$ & $\mathrm{b}=-0.062 p=0.738$ & $-\mathrm{b}=0.250 p=0.373$ & $\mathrm{~b}=-0.175 p=0.319$ & $\mathrm{~b}=0.286 p=0.236$ \\
\hline \multirow[t]{3}{*}{ Putamen } & AP & $\mathrm{b}=0.168 p=0.324$ & $\mathrm{~b}=0.237 p=0.451$ & $\mathrm{~b}=0.008 p=0.962$ & $\mathrm{~b}=0.136 p=0.578$ \\
\hline & BZD & $\mathrm{b}=-0.033 p=0.840$ & $\mathrm{~b}=0.195 p=0.441$ & $\mathrm{~b}=-0.067 p=0.662$ & $\mathrm{~b}=0.185 p=0.456$ \\
\hline & $\begin{array}{l}\text { PANSS/onset } \\
\text { age }\end{array}$ & $\mathrm{b}=-0.022 p=0.894$ & $-\mathrm{b}=0.145 p=0.637$ & $\mathrm{~b}=-0.352 p=0.028$ & $-\mathrm{b}=0.139 p=0.627$ \\
\hline \multirow[t]{3}{*}{ Thalamus } & $\mathrm{AP}$ & $\mathrm{b}=-0.336 p=0.050$ & $-\mathrm{b}=0.135 p=0.605$ & $\mathrm{~b}=-0.421 p=0.016^{*}$ & $-\mathrm{b}=0.177 p=0.364$ \\
\hline & BZD & $\mathrm{b}=0.043 p=0.794$ & $\mathrm{~b}=0.444 p=0.050$ & $\mathrm{~b}=-0.011 p=0.941$ & $\mathrm{~b}=0.460 p=0.031$ \\
\hline & $\begin{array}{l}\text { PANSS/onset } \\
\text { age }\end{array}$ & $\mathrm{b}=-0.111 p=0.508$ & $-\mathrm{b}=0.087 p=0.734$ & $\mathrm{~b}=-0.085 p=0.592$ & $\mathrm{~b}=0.008 p=0.971$ \\
\hline \multirow[t]{3}{*}{ Hippocampus } & $\mathrm{AP}$ & $\mathrm{b}=-0.232 p=0.201$ & $\mathrm{~b}=0.202 p=0.289$ & $\mathrm{~b}=-0.317 \mathrm{p}=0.078$ & $-\mathrm{b}=0.034 \mathrm{p}=0.828$ \\
\hline & BZD & $\mathrm{b}=-0.055 p=0.755$ & $b=0.479 p=0.007^{*}$ & $\mathrm{~b}=-0.105 p=0.523$ & $\mathrm{~b}=0.540 p=0.005^{\star}$ \\
\hline & $\begin{array}{l}\text { PANSS/onset } \\
\text { age }\end{array}$ & $\mathrm{b}=-0.061 p=0.734$ & $b=-0.398 p=0.046$ & $\mathrm{~b}=-0.136 p=0.416$ & $-\mathrm{b}=0.111 p=0.554$ \\
\hline \multirow[t]{3}{*}{ Accumbens } & $\mathrm{AP}$ & $\mathrm{b}=-0.375 p=0.033^{*}$ & $\mathrm{~b}=0.415 p=0.071$ & $\mathrm{~b}=-0.460 p=0.011^{*}$ & $\mathrm{~b}=0.063 p=0.725$ \\
\hline & BZD & $\mathrm{b}=0.132 p=0.430$ & $\mathrm{~b}=0.226 p=0.203$ & $\mathrm{~b}=0.106 p=0.505$ & $\mathrm{~b}=0.033 p=0.857$ \\
\hline & $\begin{array}{l}\text { PANSS/onset } \\
\text { age }\end{array}$ & $\mathrm{b}=-0.048 p=0.777$ & $b=-0.517 p=0.027$ & $\mathrm{~b}=-0.139 p=0.393$ & $\mathrm{~b}=0.429 p=0.058$ \\
\hline
\end{tabular}

ICV = intracranial volume, $\mathrm{b}=$ standardized beta, ap = antipsychotic, bzd = benzodiazepine.

* Statistically significant $(p<0.05)$ after Benjamini-Hochberg correction.

illnes and severity of symptoms all may have an effect on brain structures.

In this study we wanted to expand the focus of antipsychotic effects also to additionally include affective psychoses, in which we hypothesized that the effect would be similar to that of schizophrenia. Though there were statistically significant associations in the interaction analyses indicating that there are differential effects of antipsychotics between groups, it may be due to the fact that the individuals with affective psychoses in our sample had higher onset age (i.e. shorter duration of illness) and partly because of this, the duration of medication and lifetime antipsychotic doses were much lower than in the schizophrenia group.

Based on our systematic review, several previous studies have not found associations between antipsychotics and brain morphology in affective psychoses (Table 2). The only positive findings regarding antipsychotics and brain structures were made in studies investigating the duration of treatment (Liberg et al., 2015; Morgan et al., 2007), which may also be a measure of illness severity instead of measuring a pure medication effect. Though not many studies focus on affective psychoses and antipsychotic medications, there are studies on medication effects in affective disorders in general. A review on medication effects on neuroimaging findings in bipolar disorder concluded that the effects of psychotrophic medications such as lithium or antipsychotics are predominantly normalizing and do not seem to affect the differences observed in volumes, white matter tracts or BOLD signal between bipolar disorder patients and healthy controls (Hafeman et al., 2012). However, the observation of a normalizing effect may also relate to cross sectional designs or short follow-up periods of original studies, and there is not much knowledge on long-term associations in affective disorders.

\subsection{Benzodiazepine use and brain volumes}

There are no previous cross-sectional studies on the association between benzodiazepine doses or use and brain structures measured with MRI in psychoses. In previous computed tomography studies, benzodiazepine use has not been associated with brain volumes (Busto et al., 2000; Lader et al., 1984; Moodley et al., 1993; Perera et al., 1987), with the exception of an association between benzodiazepines and increased ventricle-to-brain ratio (Schmauss and Krieg, 1987; Uhde and Kellner, 1987). In our previous longitudinal study on NFBC1966 data including a partly overlapping sample of individuals with schizophrenia, we found that higher benzodiazepine doses during the 9-year follow-up were associated with a decrease in volume of the caudate 
nucleus after controlling for antipsychotic doses and PANSS average score (Huhtaniska et al., 2017b).

In this study, lifetime benzodiazepine doses did not associate with the volume of any brain structures in schizophrenia at the age of 43 years, when antipsychotic doses were also taken into account. In this sample, individuals with schizophrenia had used much more antipsychotics (mean dose 20.1 DDDy) than benzodiazepines (mean dose 9.1 DDDy), and thus it might be hard to distinguish the effect of these two medications. Furthermore, in schizophrenia, higher lifetime benzodiazepine doses may indicate a more severe illness (Takita et al., 2016), since polypharmacy including antipsychotics and benzodiazepines has been linked to poorer outcome (Längle et al., 2012).

On the other hand, in the affective psychoses group, higher lifetime benzodiazepine doses associated with larger volumes in total gray matter and the hippocampus even after controlling for antipsychotic dose and PANSS total score or onset age. Contrary to the schizophrenia group, the lifetime use of antipsychotics was lower (mean dose 3.8 DDDy) than lifetime use of benzodiazepines (mean dose 5.8 DDDy), which might partly explain this finding. The practices for prescribing benzodiazepines might also be different in these two patient groups (Clark et al,. 2004).

Since there are not many studies examining the association of benzodiazepines and brain structures, there are neither known mechanisms of how these medications might affect brain structures. However, in animal studies benzodiazepine exposure has been found to decrease brain derived neurotrophic factor levels (Licata et al., 2013) and other transcripts involved in synaptic functions and neural plasticity (Huopaniemi et al., 2004) and decrease the density of the spines of pyramidal neurons (Curto et al., 2016). When considering these previous findings, our results regarding larger gray matter volumes and higher lifetime doses are unexpected.

\subsection{Function of brain areas with significant findings}

Structural alterations often cause changes in the function as well and vice versa (Keck et al., 2011). The function of the brain areas that were associated to antipsychotic dose in our sample are often impaired in schizophrenia. Nucleus accumbens plays a key role in reward circuitry and action selection, integrating cognitive and affective information (Floresco, 2015) and thalamus contributes to attentional control and may associate to cognitive flexibility (Halassa and Kastner, 2017).

Larger gray matter volume has been associated with better cognitive abilities and physical functioning (Firth et al., 2017; Fletcher et al., 2018; Kubota et al., 2015). Though our findings are exploratory in nature, one potential explanation behind the association between benzodiazepine dose and larger gray matter volumes in affective psychoses could be, that benzodiazepine use with appropriate doses may help maintaining a better level of functioning after eliminating excess anxiety and hence associate with greater gray matter volumes.

\subsection{Strengths and limitations}

This study utilizes naturalistic birth cohort data, thus the sample is not selected and it may represent the clinical variability more realistically. In this natural setting it was possible to compare schizophrenia cases with cases with history of affective psychoses and to study both subgroups for association of lifetime antipsychotic or benzodiazepine doses with brain structure measurements at the age of 43 years. Our data is very heterogenous representing different stages of the disease including individuals in remission, more severely ill and with active psychosis.

To our knowledge, there are no other studies with data on lifetime use of antipsychotics and benzodiazepines in individuals with schizophrenia or affective psychoses. The medication data has been collected very comprehensively by scrutinizing all available medical records and interviewing all subjects carefully at the time of the study.

The main limitation of this study is the small sample size and the different number of cases in patient groups. Especially the number of medicated cases is limited in the affective psychoses group. Acknowledging the small sample size and that there are no previous studies on topic regarding benzodiazepine effects on brain volumes, there is a possibility that our findings may be by chance and the results must be interpreted with caution and considered exploratory and hypothesis generating rather than being conclusive. However, the findings regarding schizophrenia cases are in line with our previous longitudinal studies (Guo et al., 2015; Huhtaniska et al., 2017b; Veijola et al., 2014).

The differences in background variables may also affect our results. The gender distribution was significantly different between the groups: in the affective psychoses $68 \%$ of the subjects were female vs. $39 \%$ in the schizophrenia group. In addition, the differences in marital status, age at illness onset, and severity of illness between the groups may affect the results. There were also differences in the background variables between the groups that we could not control for in our analyses due to lack of power. We had no data on symptom severity covering the whole illness course, which could have provided a more reliable measure of illness severity. We were not able to study or take into account the use of other treatment methods such as psychosocial treatments or ECT due to lack of data. In addition we were unable to study or control for persistent anxiety and insomnia, which may lead to long-term treatment with benzodiazepines and could potentially confound our results. The lack of a healthy comparison group is also a limitation.

The cross-sectional design cannot answer the question whether there is an actual change in the brain structure volumes associated to medication, but unfortunately we do not have longitudinal data on brain changes in affective psychoses, though we have reported longitudinal findings in schizophrenia cases from this sample (Huhtaniska et al., 2017b). However, it could be presumed, that if these medications associate to brain structures in a longitudinal design, we would also detect associations when examining lifetime medication exposure in a cross sectional design. In addition, it is unfortunate, that we were not able to examine cortical volumes in detail, since our imaging data did not allow it, and thus it is possible, that cortical volume findings were left undetected.

Though the medication data was collected very thoroughly, we cannot exclude the potential confounding effects of other psychotropic or somatic medications, such as antidepressants or mood stabilizers. Especially the use of lithium could confound the results, but since in this sample there were no subjects that had used lithium during their whole lifetime, there was no need to take it into account. Unfortunately we didn't have data for other life-time mood stabilizer use. However, at the time of the study, seven cases with schizophrenia and five with affective psychoses used mood stabilizers. In addition, many individuals had used several different antipsychotics including both typical and atypical medications, and we could not study separately the effects of independent drugs.

\subsection{Conclusions}

Our findings underline the importance of taking benzodiazepine use and illness severity measures into account when studying antipsychotic effects on the brain. Since the detected effects between lifetime benzodiazepine dose and brain volumes were moderate in size, the effect should be studied further in larger populations to check if our findings are true, by chance, or explained by factors we were not able to control for. In addition, more studies focusing on affective psychoses and medication effects on brain structures are necessary. Further studies should also focus on how these findings correspond to cognition and functioning. 


\section{Conflicts of interest}

None.

\section{Funding}

This work was supported by grants from the Academy of Finland (grant numbers 132 071, 278 286, 268 336), the Sigrid Jusélius Foundation, the Brain \& Behavior Research Foundation, the Orion Research Foundation sr, the Foundation for Psychiatric Research, The scholarship Fund of the University of Oulu - Tyyni Tani Found, the University of Oulu Scholarship Foundation, the Jalmari and Rauha Ahokas Foundation, The Maud Kuistila Memorial Foundation, the Jane and Aatos Erkko Foundation, and the Oy H Lundbeck Ab. The funders had no role in the study design, data collection, data analysis, interpreting the results or the decision to publish the article.

\section{Supplementary materials}

Supplementary material associated with this article can be found, in the online version, at doi:10.1016/j.pscychresns.2018.08.015.

\section{References}

Andreasen, N.C., Carpenter, W.T.r., Kane, J.M., Lasser, R.A., Marder, S.R., Weinberger, D.R., 2005. Remission in schizophrenia: proposed criteria and rationale for consensus. Am J Psychiatry 162, 441-449. https://doi.org/10.1176/appi.ajp.162.3.441.

Arnold, S.J., Ivleva, E.I., Gopal, T.A., Reddy, A.P., Jeon-Slaughter, H., Sacco, C.B., et al., 2015. Hippocampal volume is reduced in schizophrenia and schizoaffective disorder but not in psychotic bipolar I disorder demonstrated by both manual tracing and automated parcellation (FreeSurfer). Schizophr. Bull. 41, 233-249. https://doi.org/ 10.1093/schbul/sbu009.

Baandrup, L., Fagerlund, B., Glenthoj, B., 2017. Neurocognitive performance, subjective well-being, and psychosocial functioning after benzodiazepine withdrawal in patients with schizophrenia or bipolar disorder: a randomized clinical trial of add-on melatonin versus placebo. Eur. Arch. Psychiatry Clin. Neurosci. 267, 163-171. https://doi. org/10.1007/s00406-016-0711-8.

Bora, E., Yucel, M., Fornito, A., Berk, M., Pantelis, C., 2008. Major psychoses with mixed psychotic and mood symptoms: are mixed psychoses associated with different neurobiological markers? Acta Psychiatr. Scand. 118, 172-187. https://doi.org/10. 1111/j.1600-0447.2008.01230.x.

Brown, G.G., Lee, J.S., Strigo, I.A., Caligiuri, M.P., Meloy, M.J., et al., 2011. Voxel-based morphometry of patients with schizophrenia or bipolar I disorder: a matched control study. Psychiatry Res. 194, 149-156. https://doi.org/10.1016/j.pscychresns.2011. 05.005.

Busatto, G.F., 2013. Structural and functional neuroimaging studies in major depressive disorder with psychotic features: a critical review. Schizophr. Bull. 39, 776-786. https://doi.org/10.1093/schbul/sbt054.

Busto, U.E., Bremner, K.E., Knight, K., Brugge, K., Sellers, E.M., 2000. Long-term benzodiazepine therapy does not result in brain abnormalities. J. Clin. Psychopharmacol. 20, 2-6.

Clark, R.E., Xie, H., Brunette, M.F., 2004. Benzodiazepine prescription practices and substance abuse in persons with severe mental illness. J. Clin. Psychiatry 65, 151-155.

Coryell, W., Nopoulos, P., Drevets, W., Wilson, T., Andreasen, N.C., 2005. Subgenual prefrontal cortex volumes in major depressive disorder and schizophrenia: diagnostic specificity and prognostic implications. Am. J. Psychiatry 162, 1706-1712. https:// doi.org/10.1176/appi.ajp.162.9.1706.

Cui, L., Li, M., Deng, W., Guo, W., Ma, X., Huang, C., et al., 2011. Overlapping clusters of gray matter deficits in paranoid schizophrenia and psychotic bipolar mania with family history. Neurosci. Lett. 489, 94-98. https://doi.org/10.1016/j.neulet.2010. 11.073 .

Curto, Y., Garcia-Mompo, C., Bueno-Fernandez, C., Nacher, J., 2016. Chronic benzodiazepine treatment decreases spine density in cortical pyramidal neurons. Neurosci. Lett. 613, 41-46. https://doi.org/10.1016/j.neulet.2015.12.048.

Dorph-Petersen, K.A., Pierri, J.N., Perel, J.M., Sun, Z., Sampson, A.R., Lewis, D.A., 2005. The influence of chronic exposure to antipsychotic medications on brain size before and after tissue fixation: a comparison of haloperidol and olanzapine in macaque monkeys. Neuropsychopharmacology 30, 1649-1661.

El-Sayed, M., Steen, R.G., Poe, M.D., Bethea, T.C., Gerig, G., Lieberman, J., et al., 2010. Brain volumes in psychotic youth with schizophrenia and mood disorders. J. Psychiatry Neurosci. 35, 229-236.

First, M., Spitzer, R., Gibbon, M., Williams, J., 2002. Structured Clinical Interview for DSM-IV-TR Axis I Disorders, Research Version, Patient Edition with Psychotic Screen (SCID-I/P W/PSYSCREEN). Biometrics Research, New York State Psychiatric Institute, New York, NY.

Firth, J., Cotter, J., Carney, R., Yung, A.R., 2017. The pro-cognitive mechanisms of physical exercise in people with schizophrenia. Br. J. Pharmacol. 174, 3161-3172. https://doi.org/10.1111/bph.13772.

Fletcher, E., Gavett, B., Harvey, D., Farias, S.T., Olichney, J., Beckett, L., et al., 2018. Brain volume change and cognitive trajectories in aging. Neuropsychology 32, 436-449. doi:10.1037/neu0000447.

Floresco, S.B., 2015. The nucleus accumbens: an interface between cognition, emotion, and action. Annu. Rev. Psychol. 66, 25-52. https://doi.org/10.1146/annurev-psych010213-115159.

Fond, G., Berna, F., Boyer, L., Godin, O., Brunel, L., Andrianarisoa, M., et al., 2018. Benzodiazepine long-term administration is associated with impaired attention/ working memory in schizophrenia: results from the national multicentre FACE-SZ data set. Eur. Arch. Psychiatry Clin. Neurosci. 268, 17-26. https://doi.org/10.1007/ s00406-017-0787-9.

Fontanella, C.A., Campo, J.V., Phillips, G.S., Hiance-Steelesmith, D.L., Sweeney, H.A., Tam, K., et al., 2016. Benzodiazepine use and risk of mortality among patients with schizophrenia: a retrospective longitudinal study. Benzodiazepine use and risk of mortality among patients with schizophrenia: a retrospective longitudinal study. J. Clin. Psychiatry 77, 661-667. https://doi.org/10.4088/JCP.15m10271.

Fusar-Poli, P., Smieskova, R., Kempton, M.J., Ho, B.C., Andreasen, N.C., Borgwardt, S., 2013. Progressive brain changes in schizophrenia related to antipsychotic treatment? A meta-analysis of longitudinal MRI studies. Neurosci. Biobehav. Rev. 37, 1680-1691. https://doi.org/10.1016/j.neubiorev.2013.06.001.

Giakoumatos, C.I., Nanda, P., Mathew, I.T., Tandon, N., Shah, J., Bishop, J.R., et al., 2015. Effects of lithium on cortical thickness and hippocampal subfield volumes in psychotic bipolar disorder. J. Psychiatr. Res. 61, 180-187. https://doi.org/10.1016/j. jpsychires.2014.12.008.

Guo, J., Huhtaniska, S., Miettunen, J., Jääskeläinen, E., Kiviniemi, V., Nikkinen, J., et al., 2015. Longitudinal regional brain volume loss in schizophrenia: Relationship to antipsychotic medication and change in social function. Schizophr. Res. 168, 297-304. https://doi.org/10.1016/j.schres.2015.06.016.

Hafeman, D.M., Chang, K.D., Garrett, A.S., Sanders, E.M., Phillips, M.L., 2012. Effects of medication on neuroimaging findings in bipolar disorder: an updated review. Bipolar Disord. 14, 375-410. https://doi.org/10.1111/j.1399-5618.2012.01023.x.

Haijma, S.V., Van Haren, N., Cahn, W., Koolschijn, P.C., Hulshoff Pol, H.E., Kahn, R.S., 2013. Brain volumes in schizophrenia: a meta-analysis in over 18000 subjects. Schizophr. Bull. 39, 1129-1138. https://doi.org/10.1093/schbul/sbs118.

Halassa, M.M., Kastner, S., 2017. Thalamic functions in distributed cognitive control. Nat. Neurosci. 20, 1669-1679. https://doi.org/10.1038/s41593-017-0020-1.

Harvey, I., Persaud, R., Ron, M.A., Baker, G., Murray, R.M., 1994. Volumetric MRI measurements in bipolars compared with schizophrenics and healthy controls. Psychol. Med. 24, 689-699.

Huhtaniska, S., Jääskeläinen, E., Heikka, T., Moilanen, J.S., Lehtiniemi, H., Tohka, J., et al., 2017b. Long-term antipsychotic and benzodiazepine use and brain volume changes in schizophrenia: the Northern Finland Birth Cohort 1966 study. Psychiatry Res. 266, 73-82. https://doi.org/10.1016/j.pscychresns.2017.05.009.

Huhtaniska, S., Jääskeläinen, E., Hirvonen, N., Remes, J., Murray, G.K., Veijola, J., et al., 2017a. Long-term antipsychotic use and brain changes in schizophrenia - a systematic review and meta-analysis. Hum. Psychopharmacol. 32. https://doi.org/10.1002/hup. 2574.

Hulshoff Pol, H.E., Kahn, R.S., 2008. What happens after the first episode? A review of progressive brain changes in chronically ill patients with schizophrenia. Schizophr. Bull. 34, 354-366. https://doi.org/10.1093/schbul/sbm168.

Huopaniemi, L., Keist, R., Randolph, A., Certa, U., Rudolph, U., 2004. Diazepam-induced adaptive plasticity revealed by alphal GABAA receptor-specific expression profiling. J. Neurochem. 88, 1059-1067.

Husa, A.P., Moilanen, J., Murray, G.K., Marttila, R., Haapea, M., Rannikko, I., et al., 2017. Lifetime antipsychotic medication and cognitive performance in schizophrenia at age 43 years in a general population birth cohort. Psychiatry Res. 247, 130-138. https:// doi.org/10.1016/j.psychres.2016.10.085.

Husa, A.P., Rannikko, I., Moilanen, J., Haapea, M., Murray, G.K., Barnett, J., et al., 2014 Lifetime use of antipsychotic medication and its relation to change of verbal learning and memory in midlife schizophrenia - an observational 9-year follow-up study. Schizophr. Res. 158, 134-141. https://doi.org/10.1016/j.schres.2014.06.035.

Ivleva, E.I., Bidesi, A.S., Keshavan, M.S., Pearlson, G.D., Meda, S.A., Dodig, D., et al., 2013. Gray matter volume as an intermediate phenotype for psychosis: BipolarSchizophrenia network on intermediate phenotypes (B-SNIP). Am. J. Psychiatry 170, 1285-1296. https://doi.org/10.1176/appi.ajp.2013.13010126.

Ivleva, E.I., Bidesim, A.S., Thomas, B.P., Meda, S.A., Francis, A., Moates, A.F., et al., 2012. Brain gray matter phenotypes across the psychosis dimension. Psychiatry Res. 204, 13-24. https://doi.org/10.1016/j.pscychresns.2012.05.001.

Janssen, J., Alemán-Gómez, Y., Schnack, H., Balaban, E., Pina-Camacho, L., AlfaroAlmagro, F., et al., 2014. Cortical morphology of adolescents with bipolar disorder and with schizophrenia. Schizophr. Res. 158, 91-99. https://doi.org/10.1016/j. schres.2014.06.040.

Jurjus, G.J., Nasrallah, H.A., Olson, S.C., Schwarzkopf, S.B., 1993. Cavum septum pellucidum in schizophrenia, affective disorder and healthy controls: a magnetic resonance imaging study. Psychol. Med. 23, 319-322.

Kasai, K., Shenton, M.E., Salisbury, D.F., Onitsuka, T., Toner, S.K., Yurgelun-Todd, D., et al., 2003. Differences and similarities in insular and temporal pole MRI gray matte volume abnormalities in first-episode schizophrenia and affective psychosis. Arch Gen. Psychiatry 60, 1069-1077. https://doi.org/10.1001/archpsyc.60.11.1069.

Kay, S.R., Fiszbein, A., Opler, L.A., 1987. The positive and negative syndrome scale (PANSS) for schizophrenia. Schizophr. Bull. 13, 261-276.

Keck, T., Scheuss, V., Jacobsen, R., Wierenga, C.J., Eysel, U.T., Bonhoeffer, T., et al., 2011. Loss of sensory input causes rapid structural changes of inhibitory neurons in adult mouse visual cortex. Neuron 71, 869-882. https://doi.org/10.1016/j.neuron. 2011.06.034. 
Koo, M.S., Levitt, J.J., Salisbury, D.F., Nakamura, M., Shenton, M.E., McCarley, R.W., 2008. A cross-sectional and longitudinal magnetic resonance imaging study of cingulate gyrus gray matter volume abnormalities in first-episode schizophrenia and first-episode affective psychosis. Arch. Gen. Psychiatry 65, 746-760. https://doi.org/ 10.1001/archpsyc.65.7.746.

Kubota, M., van Haren, N.E., Haijma, S.V., Schnack, H.G., Cahn, W., Hulshoff Pol, H.E., et al., 2015. Association of IQ changes and progressive brain changes in patients with schizophrenia. JAMA Psychiatry 72, 803-812. https://doi.org/10.1001/ jamapsychiatry.2015.0712.

Lader, M.H., Ron, M., Petursson, H., 1984. Computerized axial brain tomography in longterm benzodiazepine users. Psychol. Med. 14, 203-206.

Licata, S.C., Shinday, N.M., Huizenga, M.N., Darnell, S.B., Sangrey, G.R., Rudolph, U., et al., 2013. Alterations in brain-derived neurotrophic factor in the mouse hippocampus following acute but not repeated benzodiazepine treatment. PLoS One 8 , e84806. https://doi.org/10.1371/journal.pone.0084806.

Längle, G., Steinert, T., Weiser, P., Schepp, W., Jaeger, S., Pfiffner, C., et al., 2012. Effects of polypharmacy on outcome in patients with schizophrenia in routine psychiatric treatment. Acta Psychiatr. Scand. 125, 372-381. https://doi.org/10.1111/j.1600 0447.2012.01835.x.

Leung, M., Cheung, C., Yu, K., Yip, B., Sham, P., Li, Q., et al., 2011. Gray matter in firstepisode schizophrenia before and after antipsychotic drug treatment. Anatomical likelihood estimation meta-analyses with sample size weighting. Schizophr. Bull. 37, 199-211. https://doi.org/10.1093/schbul/sbp099.

Liberg, B., Ekman, C.J., Sellgren, C., Johansson, A.G., Landén, M., 2015. Subcortical morphometry and psychomotor function in euthymic bipolar disorder with a history of psychosis. Brain Imaging Behav. 9, 333-341. https://doi.org/10.1007/s11682014-9313-0.

Mahon, P.B., Eldridge, H., Crocker, B., Notes, L., Gindes, H., Postell, E., et al., 2012. An MRI study of amygdala in schizophrenia and psychotic bipolar disorder. Schizophr. Res. 138, 188-191. https://doi.org/10.1016/j.schres.2012.04.005.

Mahon, P.B., Lee, D.S., Trinh, H., Tward, D., Miller, M.I., Younes, L., et al., 2015. Morphometry of the amygdala in schizophrenia and psychotic bipolar disorder. Schizophr. Res. 164, 199-202. https://doi.org/10.1016/j.schres.2015.02.011.

Mamah, D., Alpert, K.I., Barch, D.M., Csernansky, J.G., Wang, L., 2016. Subcortical neuromorphometry in schizophrenia spectrum and bipolar disorders. Neuroimage Clin. 11, 276-286. https://doi.org/10.1016/j.nicl.2016.02.011.

Manjón, J.V., Coupé, P., 2016. volBrain: an online MRI brain volumetry system. Front. Neuroinf. 10, 30. https://doi.org/10.3389/fninf.2016.00030.

Mathew, I., Gardin, T.M., Tandon, N., Eack, S., Francis, A.N., Seidman, L.J., et al., 2014. Medial temporal lobe structures and hippocampal subfields in psychotic disorders: findings from the Bipolar-Schizophrenia network on intermediate phenotypes (BSNIP) study. JAMA Psychiatry 71, 769-777. https://doi.org/10.1001/ jamapsychiatry.2014.453.

McDonald, C., Bullmore, E., Sham, P., Chitnis, X., Suckling, J., MacCabe, J., et al., 2005. Regional volume deviations of brain structure in schizophrenia and psychotic bipolar disorder: computational morphometry study. Br. J. Psychiatry 186, 369-377.

McDonald, C., Marshall, N., Sham, P.C., Bullmore, E.T., Schulze, K., Chapple, B., et al., 2006. Regional brain morphometry in patients with schizophrenia or bipolar disorder and their unaffected relatives. Am. J. Psychiatry 163, 478-487. https://doi.org/10. 1176/appi.ajp.163.3.478.

Moilanen, J., Huhtaniska, S., Haapea, M., Jääskeläinen, E., Veijola, J., Isohanni, M., et al., 2015. Brain morphometry of individuals with schizophrenia with and without antipsychotic medication - the Northern Finland Birth Cohort 1966 Study. Eur. Psychiatry 30, 598-605. https://doi.org/10.1016/j.eurpsy.2015.02.009.

Moilanen, J.M., Haapea, M., Jääskeläinen, E., Veijola, J.M., Isohanni, M.K., Koponen, H.J., et al., 2016. Long-term antipsychotic use and its association with outcomes in schizophrenia - the Northern Finland Birth Cohort 1966. Eur. Psychiatry 36, 7-14. https://doi.org/10.1016/j.eurpsy.2016.03.002. Epub 2016 Jun 13.

Moodley, P., Golombok, S., Shine, P., Lader, M., 1993. Computed axial brain tomograms in long-term benzodiazepine users. Psychiatry Res. 48, 135-144.

Morgan, K.D., Dazzan, P., Orr, K.G., Hutchinson, G., Chitnis, X., Suckling, J., et al., 2007. Grey matter abnormalities in first-episode schizophrenia and affective psychosis. $\mathrm{Br}$. J. Psychiatry 51 (Suppl.), 111-116. https://doi.org/10.1192/bjp.191.51.s111.

Navari, S., Dazzan, P., 2009. Do antipsychotic drugs affect brain structure? A systematic and critical review of MRI findings. Psychol. Med. 39, 1763-1777. https://doi.org/ 10.1017/S0033291709005315.

Nenadic, I., Maitra, R., Dietzek, M., Langbein, K., Smesny, S., Sauer, H., et al., 2015a. Prefrontal gyrification in psychotic bipolar I disorder vs. schizophrenia. J. Affect. Disord. 185, 104-107. https://doi.org/10.1016/j.jad.2015.06.014.

Nenadic, I., Maitra, R., Langbein, K., Dietzek, M., Lorenz, C., Smesny, S., et al., 2015b. Brain structure in schizophrenia vs. psychotic bipolar I disorder: a VBM study. Schizophr. Res. 165, 212-219. https://doi.org/10.1016/j.schres.2015.04.007.

Nykänen, S., Puska, V., Tolonen, J.P., Salo, H., Isohanni, M., Koponen, H., et al., 2016. Use of psychiatric medications in schizophrenia and other psychoses in a general population sample. Psychiatry Res. 235, 160-168. https://doi.org/10.1016/j. psychres.2015.11.013.

Olabi, B., Ellison-Wright, I., McIntosh, A.M., Wood, S.J., Bullmore, E., Lawrie, S.M., 2011. Are there progressive brain changes in schizophrenia? A meta-analysis of structural magnetic resonance imaging studies. Biol. Psychiatry 70, 88-96. https://doi.org/10. 1016/j.biopsych.2011.01.032.

Perera, K.M.H., Powell, T., Jenner, F.A., 1987. Computerized axial tomographic studies following long-term use of benzodiazepines. Psychol. Med. 17, 775-777.

Radonić, E., Henigsberg, N., Rados, M., Mimica, N., Folnegović-Smalc, V., 2008. Temporal lobe volume in disorders with psychotic features. Collegium Antropol. 32, 139-142.

Radonić, E., Rados, M., Kalember, P., Bajs-Janović, M., Folnegović-Smalc, V., Henigsberg,
N., 2011. Comparison of hippocampal volumes in schizophrenia, schizoaffective and bipolar disorder. Collegium Antropol. 35 (Suppl 1), 249-252.

Ratnanather, J.T., Poynton, C.B., Pisano, D.V., Crocker, B., Postell, E., Cebron, S., et al., 2013. Morphometry of superior temporal gyrus and planum temporale in schizophrenia and psychotic bipolar disorder. Schizophr. Res. 150, 476-483. https://doi. org $/ 10.1016 / j . s c h r e s .2013 .08 .014$

Reite, M., Reite, E., Collins, D., Teale, P., Rojas, D.C., Sandberg, E., 2010. Brain size and brain/intracranial volume ratio in major mental illness. BMC Psychiatry 10, 79. https://doi.org/10.1186/1471-244X-10-79.

Rimol, L.M., Hartberg, C.B., Nesvåg, R., Fennema-Notestine, C., Hagler Jr., D.J., Pung, C.J., et al., 2010. Cortical thickness and subcortical volumes in schizophrenia and bipolar disorder. Biol. Psychiatry 68, 41-50. https://doi.org/10.1016/j.biopsych. 2010.03.036.

Rosa, P.G., Schaufelberger, M.S., Uchida, R.R., Duran, F.L., Lappin, J.M., Menezes, P.R., et al., 2010. Lateral ventricle differences between first-episode schizophrenia and first-episode psychotic bipolar disorder: a population-based morphometric MRI study. World J. Biol. Psychiatry 11, 873-887. https://doi.org/10.3109/15622975. 2010.486042.

Rosa, P.G., Zanetti, M.V., Duran, F.L., Santos, L.C., Menezes, P.R., Scazufca, M., et al., 2015. What determines continuing grey matter changes in first-episode schizophrenia and affective psychosis? Psychol. Med. 45, 817-828. https://doi.org/10.1017/ S0033291714001895.

Salokangas, R.K., Cannon, T., Van Erp, T., Ilonen, T., Taiminen, T., Karlsson, H., et al., 2002. Structural magnetic resonance imaging in patients with first-episode schizophrenia, psychotic and severe non-psychotic depression and healthy controls. Results of the schizophrenia and affective psychoses (SAP) project. Br. J. Psychiatry 43 (Suppl.), 58-65.

Scherk, H., Falkai, P., 2006. Effects of antipsychotics on brain structure. Curr. Opin. Psychiatry 19, 145-150. https://doi.org/10.1097/01.yco.0000214339.06507.d8.

Schmauss, C., Krieg, J.C., 1987. Enlargement of cerebrospinal fluid spaces in long-term benzodiazepine abusers. Psychol. Med. 17, 869-873.

Shepherd, A.M., Laurens, K.R., Matheson, S.L., Carr, V.J., Green, M.J., 2012. Systematic meta-review and quality assessment of the structural brain alterations in schizophrenia. Neurosci. Biobehav. Rev. 36, 1342-1356. https://doi.org/10.1016/j. neubiorev.2011.12.015.

Smieskova, R., Fusar-Poli, P., Allen, P., Bendfeldt, K., Stieglitz, R.D., Drewe, J., et al., 2009. The effects of antipsychotics on the brain: What have we learnt from structural imaging of schizophrenia? - A systematic review. Curr. Pharm. Des. 15, 2535-2549.

Strakowski, S.M., DelBello, M.P., Sax, K,W., Zimmerman, M.E., Shear, P.K., Hawkins, J.M., et al., 1999. Brain magnetic resonance imaging of structural abnormalities in bipolar disorder. Arch. Gen. Psychiatry 56 (3), 254-260 1999 Mar.

Strasser, H.C., Lilyestrom, J., Ashby, E.R., Honeycutt, N.A., Schretlen, D.J., Pulver, A.E., et al., 2005. Hippocampal and ventricular volumes in psychotic and nonpsychotic bipolar patients compared with schizophrenia patients and community control subjects: a pilot study. Biol. Psychiatry 57, 633-639. https://doi.org/10.1016/j. biopsych.2004.12.009.

Takita, Y., Takaesu, Y., Ono, K., Futenma, K., Shimura, A., Murakoshi, A., et al., 2016. Association between the high-dose use of benzodiazepines and rehospitalization in patients with schizophrenia: a 2-year naturalistic study. Neuropsychiatr Dis Treat 12, 3243-3247. https://doi.org/10.2147/NDT.S118759.

Uhde, T.W., Kellner, C.H., 1987. Cerebral ventricular size in panic disorder. J. Affect. Disord. 12, 175-178.

van Erp, T.G.M., Walton, E., Hibar, D.P., Schmaal, L., Jiang, W., Glahn, D.C., et al., 2018 Cortical brain abnormalities in 4474 individuals with Schizophrenia and 5098 control subjects via the enhancing neuro imaging genetics through Meta analysis (ENIGMA) consortium. Biol. Psychiatry, pii: S0006-3223(18)31517-8. doi:10.1016/j. biopsych.2018.04.023.

Veijola, J., Guo, J.Y., Moilanen, J.S., Jääskeläinen, E., Miettunen, J., Kyllönen, M., et al., 2014. Longitudinal changes in total brain volume in schizophrenia: relation to symptom severity, cognition and antipsychotic medication. PLoS One 9, e101689. https://doi.org/10.1371/journal.pone.0101689.

Vernon, A.C., Crum, W.R., Lerch, J.P., Chege, W., Natesan, S., Modo, M., et al., 2014. Reduced cortical volume and elevated astrocyte density in rats chronically treated with antipsychotic drugs-linking magnetic resonance imaging findings to cellular pathology. Biol. Psychiatry 75https://doi.org/10.1016/j.biopsych.2013.09.012. 982890.

Vernon, A.C., Natesan, S., Modo, M., Kapur, S., 2011. Effect of chronic antipsychotic treatment on brain structure: a serial magnetic resonance imaging study with ex vivo and postmortem confirmation. Biol. Psychiatry 69, 936-944. https://doi.org/10. 1016/j.biopsych.2010.11.010.

Vita, A., De Peri, L., Deste, G., Barlati, S., Sacchetti, E., 2015. The effect of antipsychotic treatment on cortical gray matter changes in schizophrenia: Does the class matter? A meta-analysis and meta-regression of longitudinal magnetic resonance imaging studies. Biol. Psychiatry 78, 403-412. https://doi.org/10.1016/j.biopsych.2015.02.008.

WHO Collaborating Centre for Drug Statistics Methodology, 2011. Guidelines for ATC classification and DDD assignment. Norwegian Institute of Public Health, Oslo 2010.

Wood, S.J., Pantelis, C., Velakoulis, D., Yücel, M., Fornito, A., 2008. Progressive changes in the development toward schizophrenia: studies in subjects at increased symptomatic risk. Schizophr. Bull. 34, 322-329. https://doi.org/10.1093/schbul/sbm149.

Woodward, N.D., Heckers, S., 2015. Brain structure in neuropsychologically defined subgroups of schizophrenia and psychotic bipolar disorder. Schizophr. Bull. 41, 1349-1359. https://doi.org/10.1093/schbul/sbv048.

Yüksel, C., McCarthy, J., Shinn, A., Pfaff, D.L., Baker, J.T., Heckers, S., et al., 2012. Gray matter volume in schizophrenia and bipolar disorder with psychotic features. Schizophr. Res. 138, 177-182. https://doi.org/10.1016/j.schres.2012.03.003. 